\title{
Relationships between Outside and Interior Appearance Inspection and Actual Bio-Deterioration of Structural Members in Existing Wood Houses
}

\author{
Takahiro Tsuchimoto ${ }^{1}$, Satoshi Takahashi ${ }^{2}$, Hideaki Sumikura $^{3}$ and Takafumi Nakagawa ${ }^{4}$ \\ ${ }^{1}$ Dept. of Building Materials and Components, Building Research Institute (BRI), Tachihara 1, \\ Tsukuba, Ibaraki 305-0802, Japan, tutti@kenken.go.jp \\ ${ }^{2}$ Dept. of Production Engineering, Building Research Institute (BRI), Tachihara 1, Tsukuba, Ibaraki \\ 305-0802, Japan, s-taka@kenken.go.jp \\ ${ }^{3}$ Dept. of Architecture, Hiroshima University, 1-4-1 Kagamiyama, Higashi-Hiroshima City, \\ Hiroshima 739-8527, Japan, sumikura@hiroshima-u.ac.jp \\ ${ }^{4}$ Research Institute for Sustainable Humanosphere, Kyoto University, Gokasho, Uji, Kyoto 611-0011, \\ Japan,nakagawa@rish.kyoto-u.ac.jp
}

\begin{abstract}
The inspection of the used house which is necessary to be evaluated is carried out without removal of the interior or exterior finishing materials. However, where the interior or exterior appearance was degraded, there was not always a bio-deterioration of the wooden structural member in the existing wood houses. Therefore, the interior or exterior appearance of the 103 used wood houses were inspected and the bio-deterioration of all wooden structural members were investigated after removal of the finishing materials. Then, the relationships between the appearance degradation and the actual bio-deterioration of the wooden structural members in the used wood houses were studied. The results were summarized as follows:

1) The bio-deterioration of the wooden structural members were found much on 1st story rather than 2nd story, in the elder building age, in case of short eaves and in case of low foundation. The issues known experience empirically were verified numerically.

2) The tendency of the appearance degradation occurrence were the same as the tendency of the biodeterioration partially, but didn't match it entirely.

3) About $90 \%$ of the portions whose interior or exterior appearance were degraded didn't have the bio-deterioration of the wooden structural member.

4) The ratio of the portion with the bio-deterioration of the wooden structural member without appearance degradation were only $1.6 \%$.
\end{abstract}

Keywords: Appearance Inspection, Degradation, Bio-Deterioration, Used Wood House.

\section{Introduction}

It is not uncommon in Japan for wood houses to be scrapped after a family has finished using it and for a new house to be rebuilt for a new family. This makes the market for the used houses inactive and disturbs the growth of the sustainable society. Revitalizing the market for the used houses is one of the most important social issue in Japan (MLIT, 2015). One of the main factors disturbing the distribution of used wood houses is the difficulty in grasping whether structural components are decayed or damaged by termites (Cho et al., 2013). Therefore, a visual inspection of the current state of more than 100 wooden houses was carried out, and after all the finishing materials and interior / exterior materials were removed, a biological deterioration survey of all structural members was carried out. Then, we analyzed the relationship between 
appearance defects and biological deterioration of structural members.

\section{Appearance Inspection and Bio-Deterioration Survey Methods}

\subsection{Attribution of Inspected and Surveyed Houses}

Houses to be demolished for removing or renovated houses were selected (Tsuchimoto et al., 2016). This was a necessary condition for exposing all structural members and surveying the state of bio-deterioration. Since the durability can be affected by the building age, the construction methods, and the site condition, we made an effort so that the attribution of the inspected and surveyed houses didn't have any bias. Most of the construction method of the inspected and surveyed houses were Japanese conventional post and beam construction. The wood frame construction and the prefabricated wood construction were only 4 and 2 houses, respectively. It was difficult to find the relatively new house for inspection and survey. The building age distribution of the inspected and surveyed houses are shown in Table 1. The minimum and maximum building ages were 14 and 63, respectively. As for the story of the houses, most were 2-story houses, excluding ten 1-story houses and a 3-story house. The distribution of the building locations of the inspected and surveyed houses are shown in Table 2. As mentioned above, though the houses needed to be chosen without bias, the houses built at the standard region were most and occupied about $73 \%$. Because most of the houses in Japan were built in the standard region including Tokyo and Osaka.
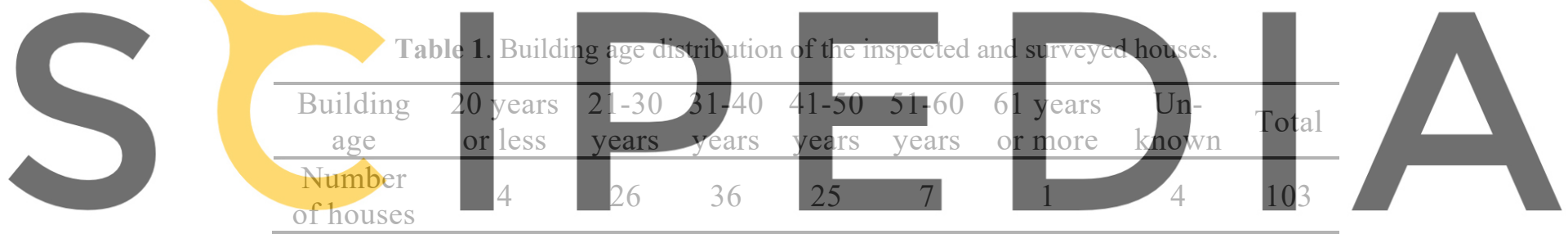

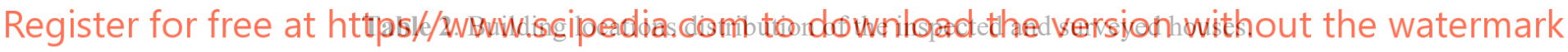

\begin{tabular}{|c|c|c|c|c|c|c|c|c|}
\hline Region & \multicolumn{3}{|c|}{ Cold region } & \multicolumn{2}{|c|}{ Standard region } & \multicolumn{2}{|c|}{$\begin{array}{l}\text { Hot and humid } \\
\text { region }\end{array}$} & \multirow{3}{*}{ Total } \\
\hline Zone No. & $1 \& 2$ & 3 & 4 & 5 & 6 & 7 & 8 & \\
\hline $\begin{array}{l}\text { Example } \\
\text { of place }\end{array}$ & Hokkaido & $\begin{array}{l}\text { North } \\
\text { Tohoku }\end{array}$ & $\begin{array}{c}\text { South } \\
\text { Tohoku }\end{array}$ & $\begin{array}{l}\text { Cool } \\
\text { area* }\end{array}$ & $\begin{array}{l}\text { Warm } \\
\text { area* }\end{array}$ & $\begin{array}{c}\text { South } \\
\text { Kyushu }\end{array}$ & Okinawa & \\
\hline $\begin{array}{l}\text { Number } \\
\text { of houses }\end{array}$ & 0 & 5 & 11 & 18 & 57 & 12 & 0 & 103 \\
\hline
\end{tabular}

*: The cool area and the warm area respectively indicate the relatively cool and warm district of North Kyushu, Shikoku and the main island of Japan excluding Tohoku.

\subsection{Method of Appearance Inspection}

As the appearance inspection, the interior and exterior materials and the finishing material of the house, for example, shown in Photo 1(a) were observed (Photo 1(b)), and their degradation such as rain leak marks, cracks, discoloration and so on were grasped. The location and degree of these deteriorations were visually measured with reference to "Durability design and maintenance / deterioration diagnosis of wood houses" (2002) issued by the Japan Housing and 
Wood Technology Center.

\subsection{Method of Bio-Deterioration Survey of All Structural Members}

The bio-deterioration survey were conducted to all structural members after the removal of all sheathings and finishing materials (Photo 1(c)). The visual and tactile inspection were conducted to survey all structural members for bio-deterioration. The bio-deterioration includes the decay and the termite damage. The position and degree of the deterioration were grasped and recorded with reference to the above-mentioned manual issued by HOWTEC.

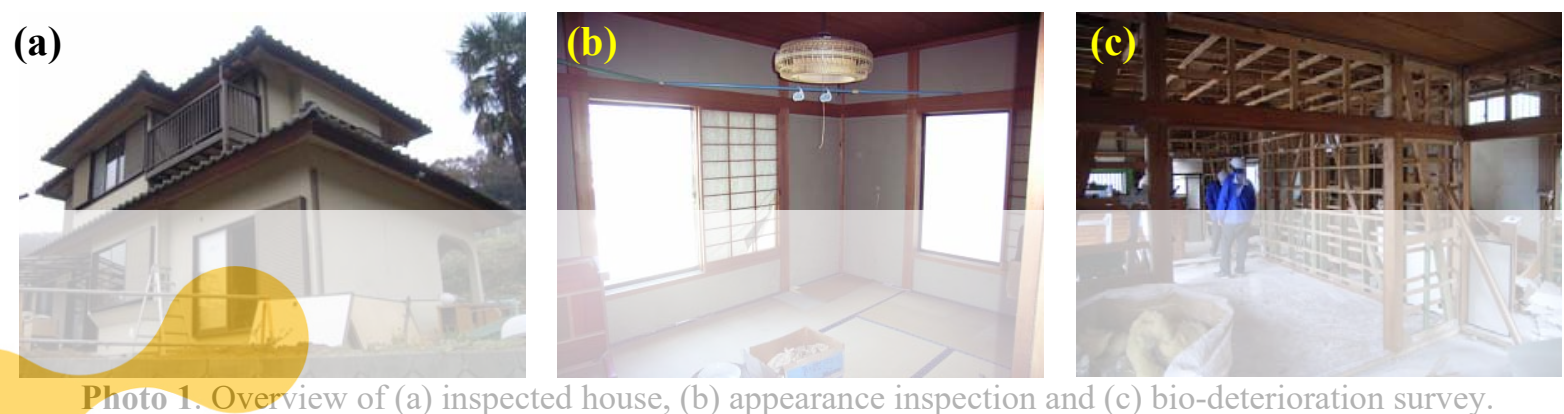

\section{Database of Inspection and Survey Results}
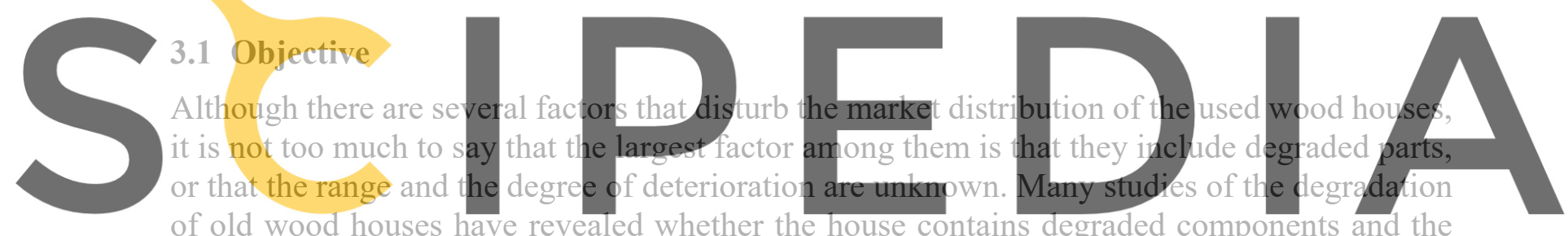
tendency for degradation to exist. But even if you know these things, the buy.ers cannot decide

endure. Therefore, it is necessary to evaluate not only whether or not the degradation has occurred but also in what range and how serious the bio-deterioration is.

Then, the inspected and surveyed houses were divided into square segments of approximately $900 \mathrm{~mm}$, each linked to the results of appearance inspections and to the results of bio-deterioration survey of all structural members, including the degree of decay or termite damage. Each segment is not necessarily independent, but the number of segments indicates the range of degradation. In other words, minor deterioration is one segment, but widespread degradation is two or more segments. And, the relationship between the appearance defect and the bio-deterioration of the structural member was analyzed.

\subsection{Compilation Method into Database}

At first, the investigated houses were divided into roofs, walls, and floors of the $1^{\text {st }}$ and $2^{\text {nd }}$ story, respectively. The roof segment and the $2^{\text {nd }}$ floor segment include the ceiling and the $1^{\text {st }}$ story's ceiling, respectively. The wall segments included the interior sheathings and the exterior finishing material. Next, as shown in Figure 1, the wall, floor and roof were divided into approximately $900 \mathrm{~mm}$ square segments. The wall with the opening was divided into the 
hanging wall and spandrel wall segments. As a result, 103 homes were divided into approximately 65,000 segments. Each segment linked to the attribution of the investigated houses and the information of the appearance degradation and the bio-deterioration of the structural members included in it.
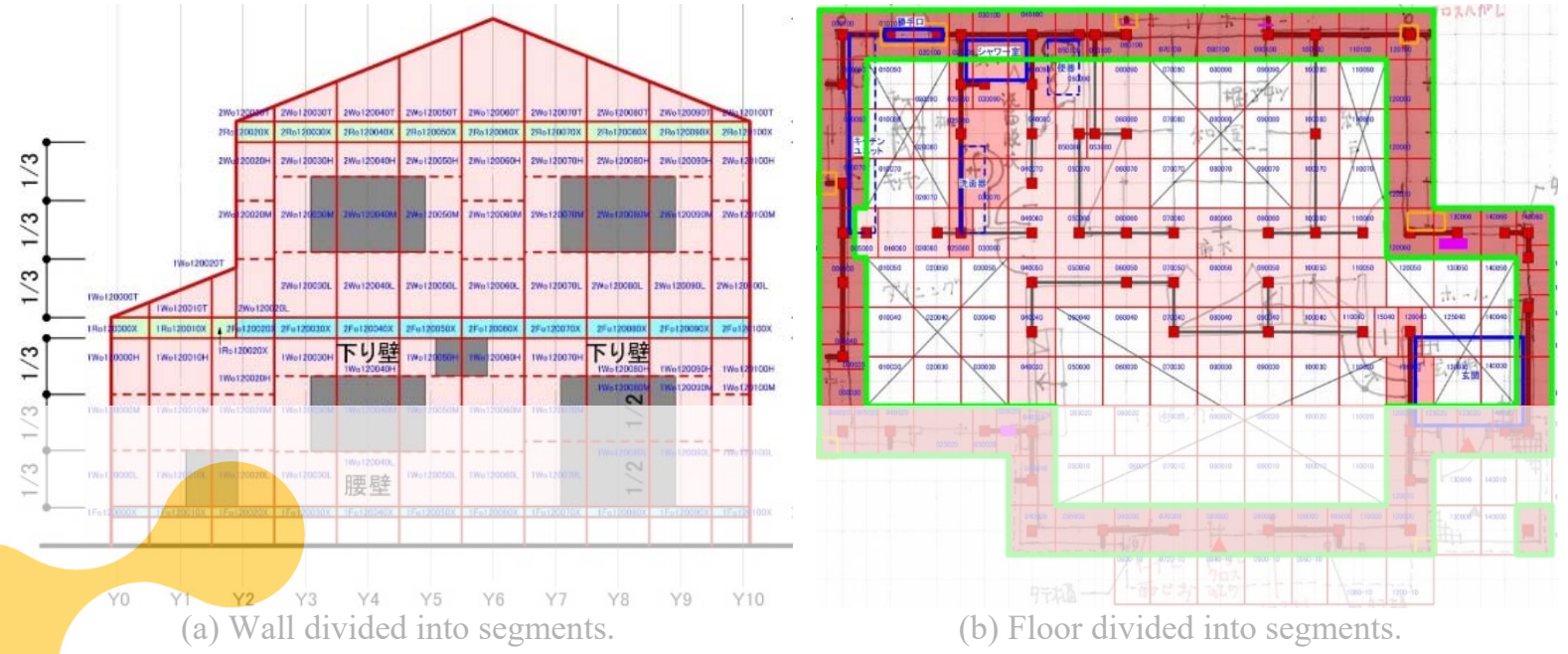

Figure 1. Dividing method of investigated house into segments.
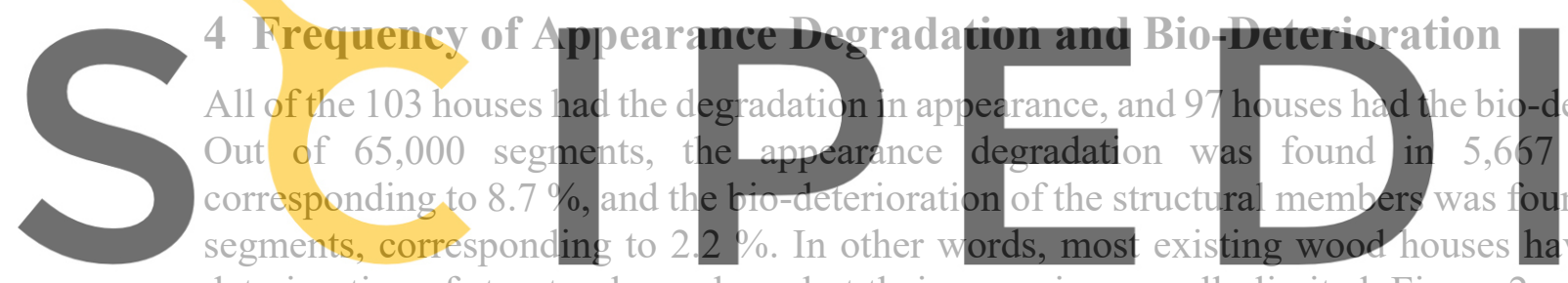

deterioration of structural members, but their range is generally limited. Figure 2 and 3 shows

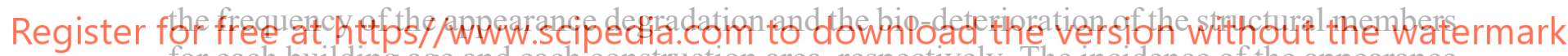

for each building age and each construction area, respectively. The incidence of the appearance

degradation and the bio-deterioration increased with older building age, except for over 50 years

whose sample was very few. The incidence of them was lowest in zone No. 7 with high temperature and humidity. In others, the incidence increased in warmer zone, except for zone No. 3 where the sample was very small.

Figure 4 shows the incidence of them for each building part. Both of the appearance degradation and the bio-deterioration of the structural member often occurred on the $1^{\text {st }}$ story and outside rather than the $2^{\text {nd }}$ story and inside, respectively.

Figure 5 shows the relationships between the construction method and height of the foundation and the bio-deterioration of the structural member in the $1^{\text {st }}$ story. The incidence of the bio-deterioration was lower in the order of the concrete mat foundation with footing, only the footing with the moisture barrier concrete and the one without the moisture barrier concrete. The mat foundation and the moisture barrier concrete are effective in preventing the biodeterioration of the structural member in the $1^{\text {st }}$ story. Although there were some exceptions, the incidence of the bio-deterioration almost decreased as the foundation height raised.

Figure 6 shows the effect of the segment orientation on the incidence of the appearance degradation and the bio-deterioration of the structural members. The orientation of the segments 
had no obvious effect on the incidence of them.

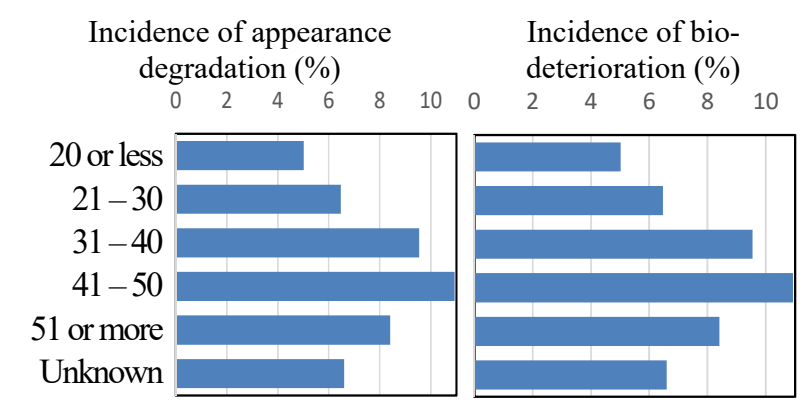

Figure 2. Incidence of the appearance degradation (left) and the bio-deterioration (right) for each building age.

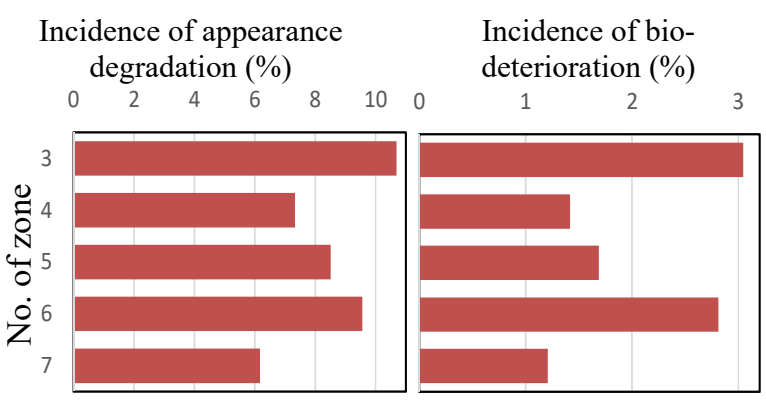

Figure 3. Incidence of the appearance degradation (left) and the bio-deterioration (right) for each building location.
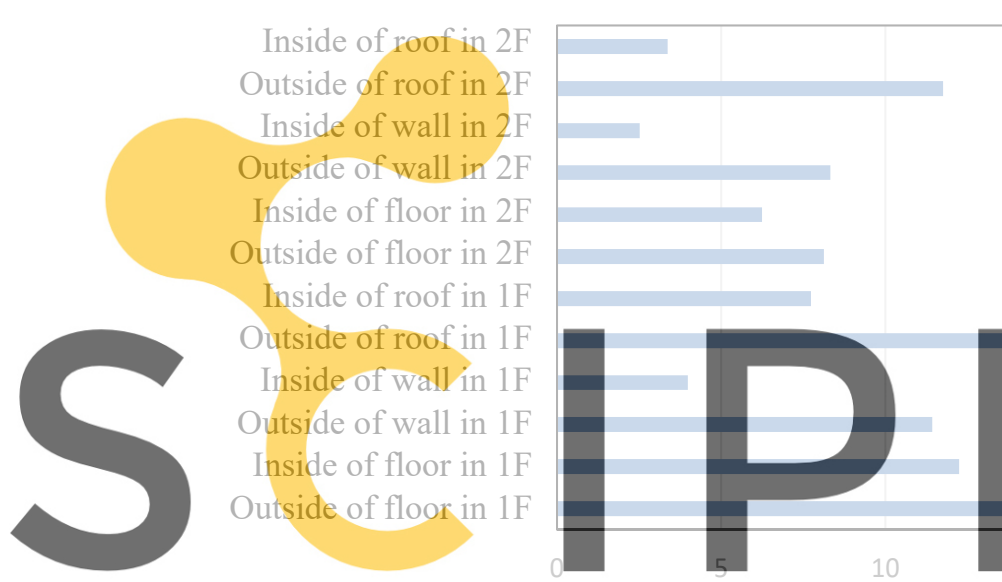

Incidence of appearance degradation (\%)

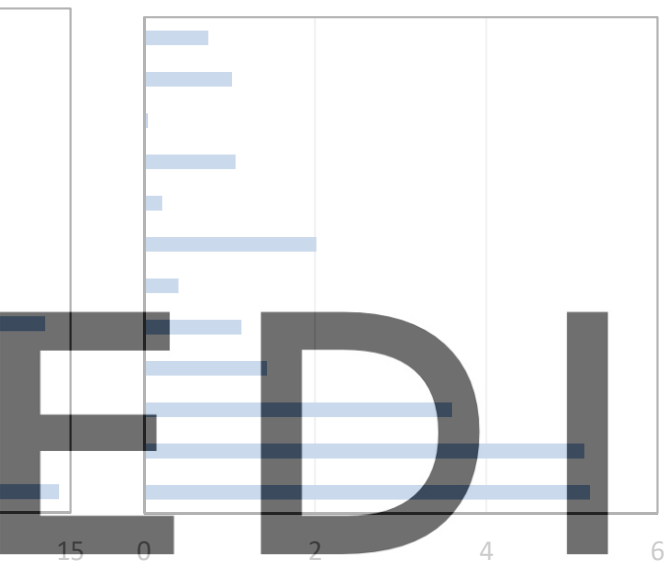

Incidence of bio-deterioration (\%)

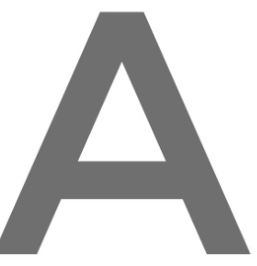

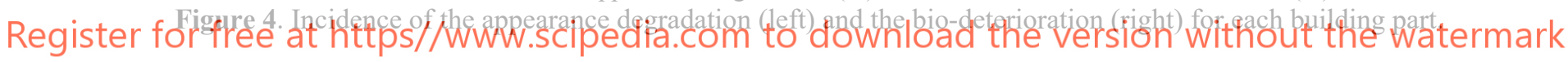
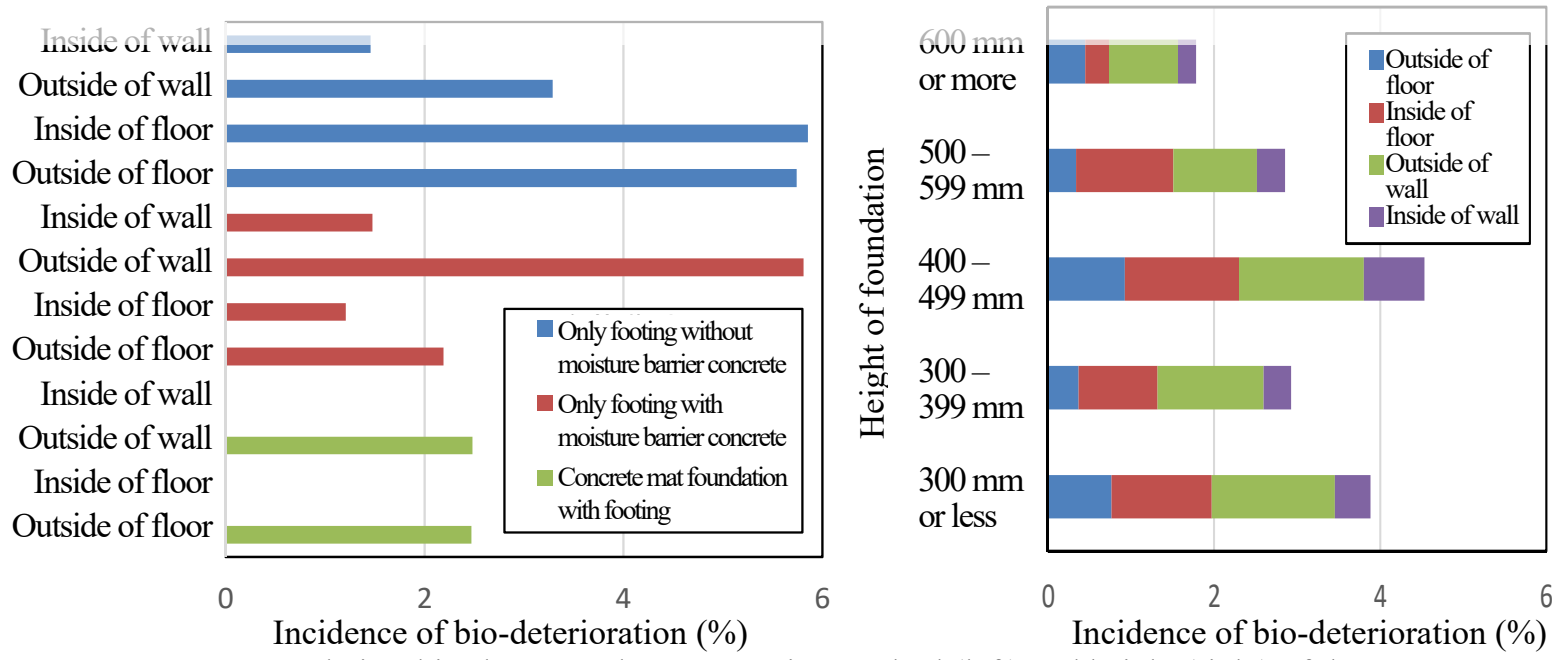

Figure 5. Relationships between the construction method (left) and height (right) of the foundation and the bio-deterioration of the structural member in the 1 st story. 
Figure 7 shows the effect of the eaves length on the incidence of the appearance degradation and the bio-deterioration of the structural members. The length of the eaves didn't clearly affect the incidence of the appearance degradation. However, as the length of the eaves increased, the incidence of the bio-deterioration almost decreased.

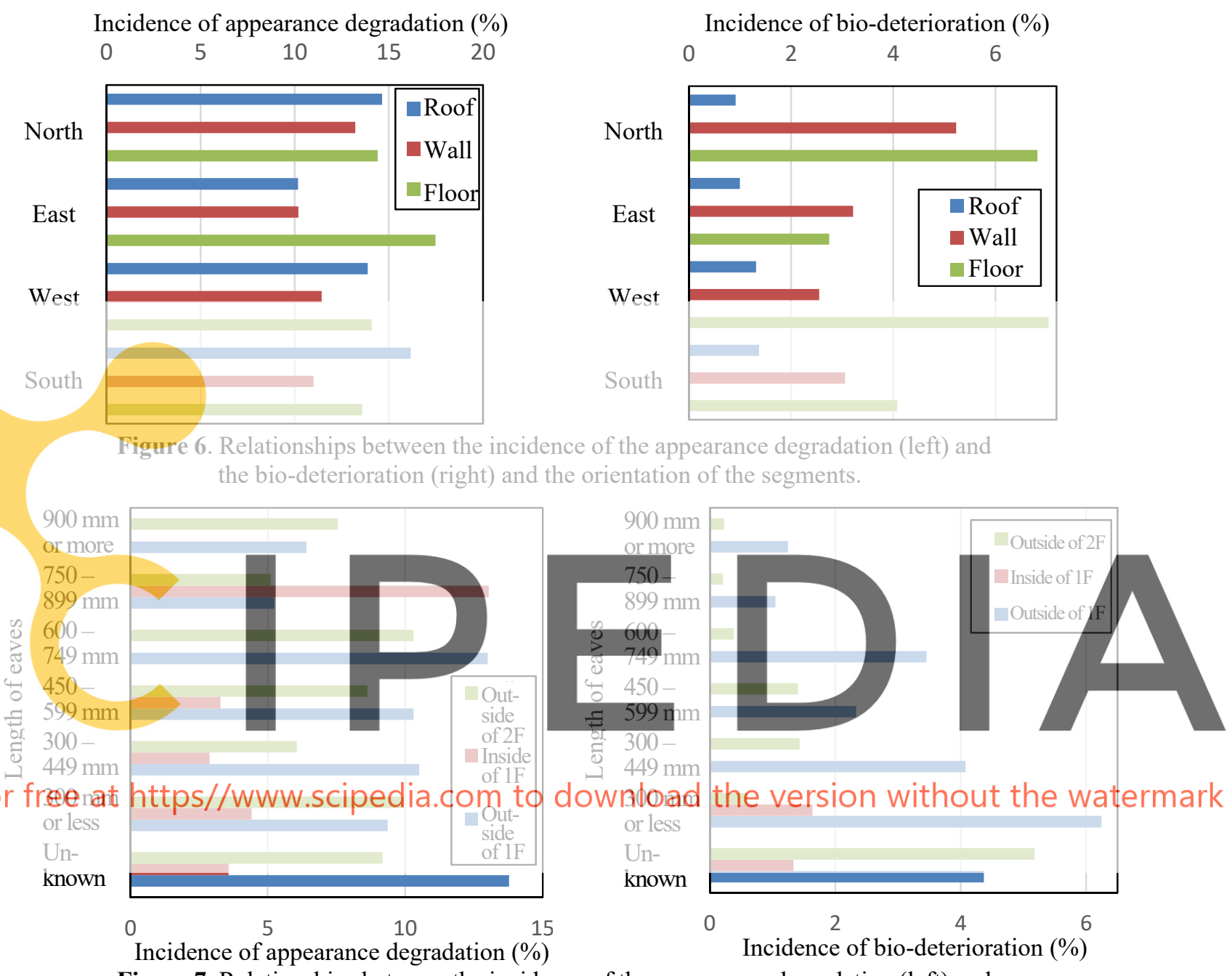

Figure 7. Relationships between the incidence of the appearance degradation (left) and the bio-deterioration (right) and the length of the eaves.

\section{Difference between Appearance Degradation and Bio-Deterioration}

On the most of the dealing with the used houses, only the appearance inspection is conducted. So, the result of the appearance inspection needs to match the position of the bio-deterioration. However, the occurrence of the appearance degradation and the bio-deterioration of structural members were not the same, as mentioned above. For example, there was no decayed member in the $2^{\text {nd }}$ floor system near the position of the rain leak mark on the ceiling of the $1^{\text {st }}$ story found by the appearance inspection, as shown in Figure 8. And, the bottom of the column decayed even though no degradation were found by the appearance inspection, as shown in Figure 9. 


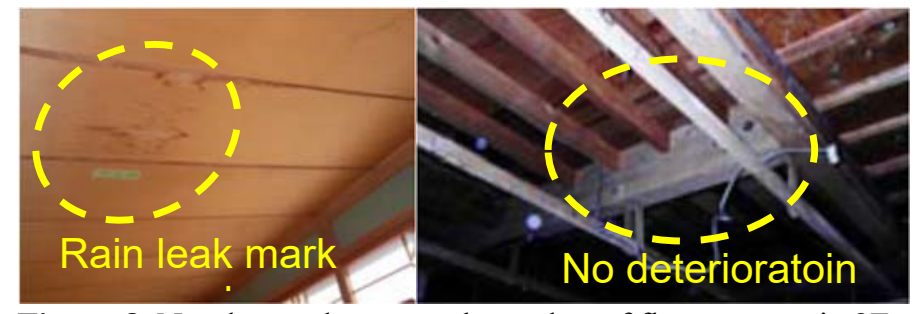

Figure 8. Not decayed structural member of floor system in $2 \mathrm{~F}$ (right) in spite of the rain leak mark on the ceiling (left).
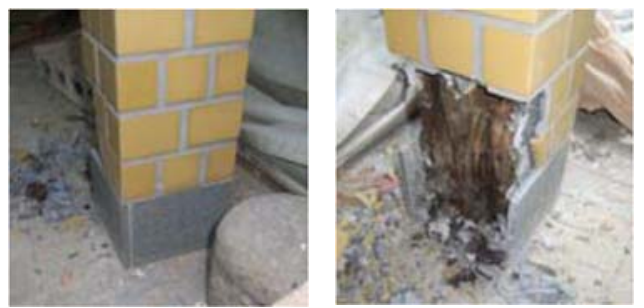

Figure 9. Decayed bottom of column (right) in spite of no degradation found by the appearance inspection.

Then, we analyzed the differences between the appearance degradation and the biodeterioration of the structural members. The number of the segments with/without appearance degradation and those with/without the bio-deterioration of the structural member were subiected to the cross tabulation, as shown Table 3. It was clarified that there was no biodeterioration in more than $90 \%$ of segments out of all with the appearance degradation (e.g. Figure 8 ), and that there was the bio-deterioration in only $1.6 \%$ of segments of all without the appearance degradation (e.g. Figure 9).

Table 3. Cross tabulation of the number of segments with/without the appearance degradation and those with/without the bio-deterioration of the structural members.
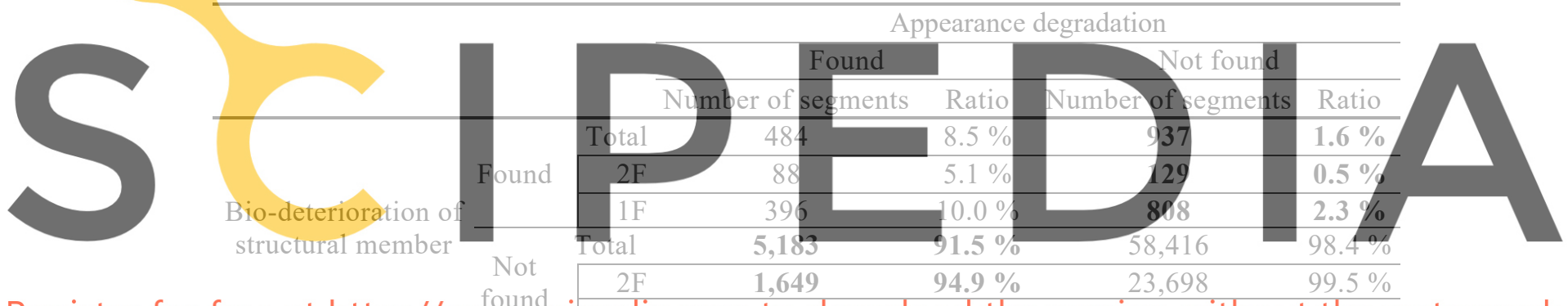

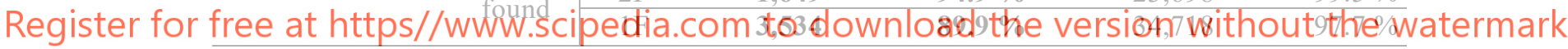
Total

\begin{tabular}{|lllll|}
\hline $2 \mathrm{~F}$ & 1,737 & $100 \%$ & 23,827 & $100 \%$ \\
\hline $1 \mathrm{~F}$ & 3,930 & $100 \%$ & 35,526 & $100 \%$ \\
\hline
\end{tabular}

Next, the distribution of segments including those differences for each building part was studied, as shown in Figure 10. The incidence of the segments with the bio-deterioration in spite of the no appearance degradation in the $1^{\text {st }}$ story was higher than that in the $2^{\text {nd }}$ story and high in the order of the floor, the wall and the roof. From these, even if the occurrence rate of such differences depends on the incidence rate of biological deterioration, the appearance degradation, the structural members in the $1^{\text {st }}$ story, especially in the floor, should be inspected or surveyed carefully, regardless of the appearance degradation. On the other hand, the distribution of the segments without the bio-deterioration in spite of the appearance degradation didn't have clear tendency for each building part and in each part the incidence was over $80 \%$. One possible reason is that it takes time for the outside rain leak to penetrate the structural members, and the water evaporates before the water reaches the structural members. 


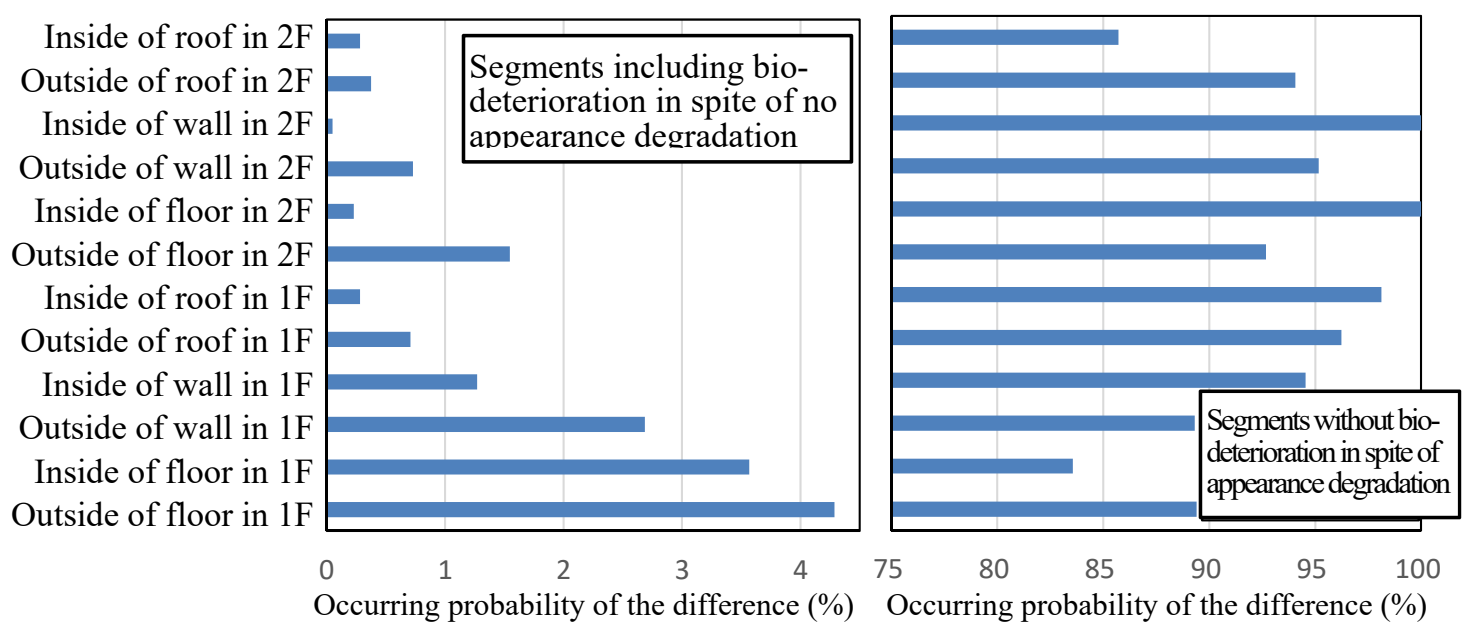

Figure 10. Distribution in each building part of the segments including the bio-deterioration in spite of no appearance degradation (left) and without the bio-deterioration in spite of appearance degradation (right).

\section{Conclusions}

The relationships between the appearance degradation and the actual bio-deterioration of the structural members obtained by the investigation for over 100 used wood houses were analyzed and concluded as follows:

\section{The bio-deterioration of the wooden structural members were found much on $1^{\text {st }}$ story}

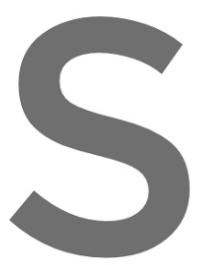
rather than $2^{\text {nd }}$ story, in the elder building age in case of short eaves and in case of low foundation. The issues known experience empirieally were verified humerically.
the tendency of the appearance degradation occurrence were the same as the tendency of
About $90 \%$ of the portions whose interior or exterior appearance were degraded didn't
have the bio-deterioration of the wooden structural member. The ratio of the portion with the bio-deterioration of the wooden structural member without

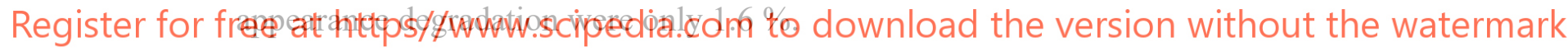

\section{Acknowledgements}

The inspection and survey for over 100 used wood houses were conducted as a part of the R\&D Project "Development on performance evaluation technologies for home inspection to reduce uncertainty of existing house" funded by The Ministry of Land, Infrastructure, Transport and Tourism (MLIT). The compilation of the inspection and survey results into the database was conducted as a part of the R\&D Project of Building Research Institute "Development of durability evaluation method of buildings materials and components for strategic maintenances".

\section{ORCID}

Takahiro Tsuchimoto: https://orcid.org/0000-0003-4925-1831

\section{References}

Cho, H. and Takada, M. (2013). A study on the characteristics of home buyer's demand and the obstructive factors of existing housing circulation - Based on the survey of targetiong existing home buyers in Osaka Prefecture (in Japanese), J. Architecture Planning, 78(8), 1817-1825, Architectural Institute of Japan, Tokyo Japan.

Ministry of Land, Infrastructure, Transport and Tourism in Japan (MLIT, 2015). Preparing a market that facilitates the smooth trading of existing houses, White Paper on Land, Infrastructure, Transport and Tourism in Japan, Chapter 5, 167-168, MLIT, Tokyo, Japan.

Tsuchimoto, T., Takahashi, S., Sumikura, H., Nakagawa, T. and Hanawa, K. (2016). Study on the differences between visual inspection and degradation diagnosis on old wood houses (in Japanese), Summaries of Technical Papers of Annual Meeting, C-1, 591-592, Architectural Institute of Japan, Tokyo, Japan. 